\title{
"I try and make my cell a positive place" Tactics for mitigating risks to health and wellbeing in a young offender institution
}

\section{Dr Anita Mehay' (corresponding author)}

School of Law, Royal Holloway, University of London, Egham, Surrey, UK, TW20 OEX

a.mehay@vel.ac.uk

\section{Professor Rosie Meek}

School of Law, Royal Holloway, University of London, Egham, Surrey, UK, TW20 OEX r.meek@rhul.ac.uk

\section{Professor Jane Ogden}

School of Psychology, University of Surrey, Guildford, UK, GU2 7XH

j.ogden@surrey.ac.uk

\footnotetext{
1 Present address: Institute for Health and Human Development (IHHD), University of East London, Water Lane, London E15 4LZ
} 